\title{
MANAGEMENT STRATEGIES FOR PREVENTION OF FOREST FIRE AND ENVIRONMENTAL DEGRADATION IN TROPICS WITH SPECIAL REFERENCE TO WESTERN GHATS OF KERALA REGION, INDIA
}

\author{
Menon ARR ${ }^{1, *}$ \& Vishnu-Menon $\mathrm{RG}^{2}$ \\ ${ }^{1}$ School of Environmental Studies, Cochin University of Science and Technology (CUSAT), Cochin-682 022, Kerala, \\ India \\ ${ }^{2}$ School of Communication, Journalism and Marketing, Massey Business School, Massey University, PO Box 756 , \\ Wellington 6140, New Zealand \\ *arrmenon@gmail.com
}

Submitted October 2020; accepted May 2021

\begin{abstract}
Management of forest fire is one of the top priority activities of forest departments, both in tropics and temperate regions. Extensive amount and intensive efforts are deployed to combat fire. The results of a case study on forest fire prone mapping conducted at Periyar tiger reserve in Western Ghats of Kerala, India, was highlighted, and based on the study, the implementation of fire management strategies were discussed. The fire risk map was validated with the forest fire inventory points of Forest Survey of India. Forest fire is a frequent occurrence in tropical forests, especially in moist deciduous and dry deciduous regions. Though forest fire management is one of the major activities of forest departments, the forest fire mitigation is not $100 \%$ successful. The magnitude of forest fire, its frequency, potential location, etc., can be assessed using Geoinformatics techniques, by giving different weightage status to fire controlling factors. A case study was conducted on these lines and control measures were highlighted using different management strategies. The implementation of the desired action plan for sustainable development and conservation of forests can be successful only by getting the full support and confidence of the stakeholders. The stakeholder support for environmental management aspects is possible only by convincing them that they are directly or indirectly getting the benefits by the proposed action. Usually, most of the environmental management activities may lead to nontangible benefits, which is apparently non-visible, hence getting stakeholder support may not be an easy task. Various marketing strategies needs to be used to convince the beneficiaries to implement good conservation practices for the betterment of the local inhabitants.
\end{abstract}

Keywords: Forest fire management, geographic information system (GIS), management strategy

\section{INTRODUCTION}

Sustainable management of the natural forest resource is a key issue for survival. Threats to the species/ecosystems are the greatest in recent times mainly due to unsustainable exploitation of biological resources and natural hazards, i.e., forest fire. Natural hazards also contribute to the loss of biodiversity and there is an urgent need to conserve gene pool in situ before it is lost forever. There could be several factors, either acting singly or in combination, leading to a forest fire, which ultimately leads to the extinction of a species or change in species composition. For generating baseline data on plant species, habitats, ecosystems and for subsequent monitoring, reliable and welldocumented information is a prerequisite.
It is interesting to note that majority of 'hot spots' are confined to species rich tropical habitats, since most tropical species are highly eco-sensitive in nature. A case study was conducted on these lines, with respect to forest fire, using geoinformatics for assessing the status of forest fire as a prerequisite, for generating management strategy.

\section{MATERIAL AND METHODS}

The ecosystem approach is a strategy for the integrated management of land, water and living resources that promotes conservation and sustainable use in an equitable way. It is based on the application of appropriate 
scientific methodologies focused on levels of biological organisation which encompass the essential processes, functions and interactions among organisms and their environment. According to the ecosystem approach, forest ecosystems should be managed for their intrinsic values and for the tangible benefits they provide to human beings, in a fair and equitable way. It is difficult to convince the stakeholders regarding the implementation of strategic actions for environmental conservation, since their interest is mainly in material gain rather than service benefits. Hence, the use of marketing strategies plays a key role in convincing stakeholders regarding service benefits, for long term use and conservation of natural resources. The implementation of the desired action plan for sustainable development and conservation can be successful only by getting the full support and confidence of the stakeholders. The stakeholder support for environmental management aspects is possible only by convincing them that they are directly or indirectly getting the benefits by the proposed action. Usually, most of the environmental management activities lead to non-tangible benefits, which is apparently non-visible, hence getting stakeholder support may not be an easy task. Thus, various marketing strategies must be used to convince the beneficiaries to implement good conservation practices for the betterment of the local inhabitants. Habitat management challenges in tropics are different to that of temperate regions. Most tropical ecosystems are rich in species, and most species occur only at a very low density, hence, large areas need to be conserved for viable population. The tropical habitat experiences more severe climatic variations. Rainfall in the tropics is much heavier while the tropical sun makes conditions hotter and drier. These factors make tropical soils highly prone to erosion, and vegetation susceptible to wildfire. The ecological amplitude of the tropical species to withstand adverse condition is always low, hence, even the minor perturbation in the habitat factors are highly lethal to the species. This makes it difficult for original vegetation to return.

Landscape composition can be measured in analogous to measurements of species composition (Romme 1988). The landscape richness measurement approach (the number of different patch types in a landscape) is a widely used method. Measurements of landscape diversity are analogous to common measurement of species diversity (Whittaker 1978).

In developing countries, the role of the state has diminished, and the market forces have increasingly taken over the dominant socioeconomic role. The market forces are not only inappropriate for sustaining the environment, but are a major cause of environmental destruction. The people cannot be left to do as they wish with land or environmental resources. Thus, decentralisation of management offers an alternative solution to forest governance. The major key to effective decentralisation is increased broad-based participation in localpublic decision making. The participatory management approach is highly essential for a better result. It is necessary to recognise and advocate for better forest governance, given the importance of forest in meeting basic human needs in the future, maintaining ecosystem and biodiversity, as well as addressing climate change mitigation and adaptation goal. Payment for environmental services (PES) schemes for forest service may be foreseen as a part of forest management implementation, providing new incentives to move towards sustainable decision patterns. Such a system should also be adopted for forest fire management.

\section{Formulation of strategies based on case studies}

The formulations of management strategies should be based on scientific facts generated, either directly from the field or based on the prediction models generated by using various modern technological innovations. The prediction models should be based upon the actual field realities, i.e., data collected from the field at different temporal stages. The management strategies and action plan for implementation, generated through scientific study and related modeling, will be more acceptable to the stakeholders in the area.

Management of forest fire is one of the top priority activities of forest departments. The occurrence of forest fire is a regular phenomenon in most areas. It is true that the 
government authorities are promoting forest fire preventing activities, as per the standard protocol of management activities. More site-specific studies, identifying the reason of forest fire and sustainable management strategies are yet to be evolved in different regions, depending on the type of vegetation and other external factors that influence the spread of forest fire. The effect of forest fire on vegetation, fauna, soil, forest types with respect to species composition, forest ecosystem continuity, geomorphologic impact, drainage patterns, regeneration and formation of vegetation, etc., are yet to be studied critically. The impact of forest fire on vegetation composition, soil condition, regeneration, species changes, forest type wise changes, continuity of cover types, animal food and fodder status, corridor changes, etc., have been studied in many parts of the world, and some site-specific case studies are also available (KFRI 2010). This information can be used for management of fire prone areas, and post fire situation for recouping the fauna and flora status of the forest.

It is also necessary to gather information regarding the fire promoting factors like, wind direction, litter production vegetation status, drainage system, water availability, fire resistant species and climatic regime of the area. By using scientific information, it will be easy to quantify the fire promoting factors at different scale, and to generate fire prone map of the area. Such maps will be helpful in preparing management strategies for fire management. Modern technological applications such as remote sensing technology and GIS technology, can be highly helpful in generating such statistical data, and to prepare fire prone area maps based on fire magnitude. Thus, the forest fire management requires studies on the impact of forest fire, quantification of fire promoting factors and magnitude of the forest fire in different situations as prerequisites for management strategy preparation.

To formulate the strategy for fire management, a case study was conducted at Periyar Tiger Reserve of Western Ghats, Kerala, India. The management strategy was evolved based on a scientific study. As the first step, various physical and demographic factors affecting the forest fire were identified, and its influence in creating and spreading fire in the forested region was critically evaluated. Using remote sensing (RS) and geographic information system (GIS) / global positioning system (GPS) technologies, the prediction model was generated and the magnitude of each factors were weighted, and accordingly corresponding weightage indices were generated. Subsequently a fire prone map was generated for further evaluation. The case study details are given in the following illustrations.

Monitoring forest fire is a very important aspect of forest management. Most fires occurring today are thought to be human caused, and considered a major cause of forest degradation. Nearly $55 \%$ of the total forest cover in India is prone to fires every year. Once the fire has started, its spread and intensity are influenced by factors like fuel (leaves, branches and grass), weather (temperature, humidity, precipitation and wind), and topography. It can cause environmental and economic damage, as well as loss of human life (Satendra \& Kausik 2014). The case study area is prone to forest fires and was affected by forest fires of the past.

\section{Technological intervention}

The GIS and RS applications have been used by numerous workers in delineation of forest fire risk zones (Chuvieco \& Congalton 1989, Jaiswal et al. 2002, Sowmya \& Somashekar 2010, Paul et al. 2011, Ghobadi et al. 2012, Chavan et al. 2012, Srivastava \& Garg 2013). The factors considered were fuel type, slope, aspect, habitation, drainage and road. Other factors such as slope, aspect, temperature, distance from roads, distance from settlements, normalised difference vegetation index (NDVI) and normalised difference water index (NDWI) were also considered for forest fire evaluation (Nambimanavalan \& Jayalakshmi, 2013). In the present case study, an attempt has been made to assess and map the potential fire prone areas of Periyar Tiger Reserve ( $76^{\circ} 55^{\prime}-$ $77^{\circ} 25^{\prime}$ E longitudes, $9^{\circ} 18^{\prime}-9^{\circ} 41^{\prime}$ N latitudes), using RS and GIS techniques. ArcGIS 9.3 and ERDAS Imagine 9.2 software tools were used for the preparation of thematic maps. A fire risk index (FRI) method was used to delineate the risk zones. The selected factors were land cover type, slope, distance from settlements, distance from roads and elevation. The 
thematic maps required for the present study were prepared by using ArcGIS 9.3 and ERDAS Imagine 9.2 software tools. The study area map (Figure1) and land cover type map (Figure 2) of the study area was derived from Landsat ETM+ image of $23.5 \mathrm{~m}$ resolution. The ERDAS Imagine software was used for supervised classification of the Landsat image. The road networks and human settlements of the study area were digitised from the survey of India topographic maps and google image.
The distance from road map (Figure 3) and distance from settlement map (Figure 4) were prepared from the digitised data by using ArcGIS spatial analyst tools. The contour data was generated from Cartosat 1 DEM of 30 $m$ resolution by using ArcGIS spatial analyst tools. The $20 \mathrm{~m}$ interval contour data was used to prepare the slope and elevation map. The ArcGIS spatial analyst and 3D analyst tools were used to prepare the slope map (Figure 5) and elevation map (Figure 6).
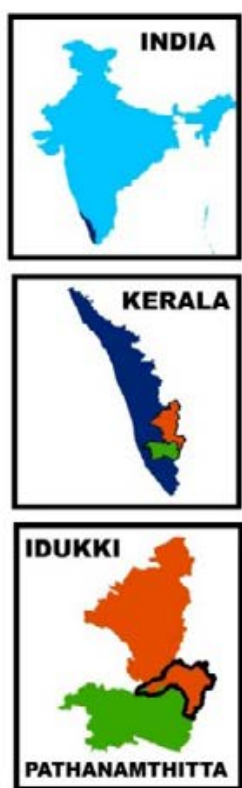

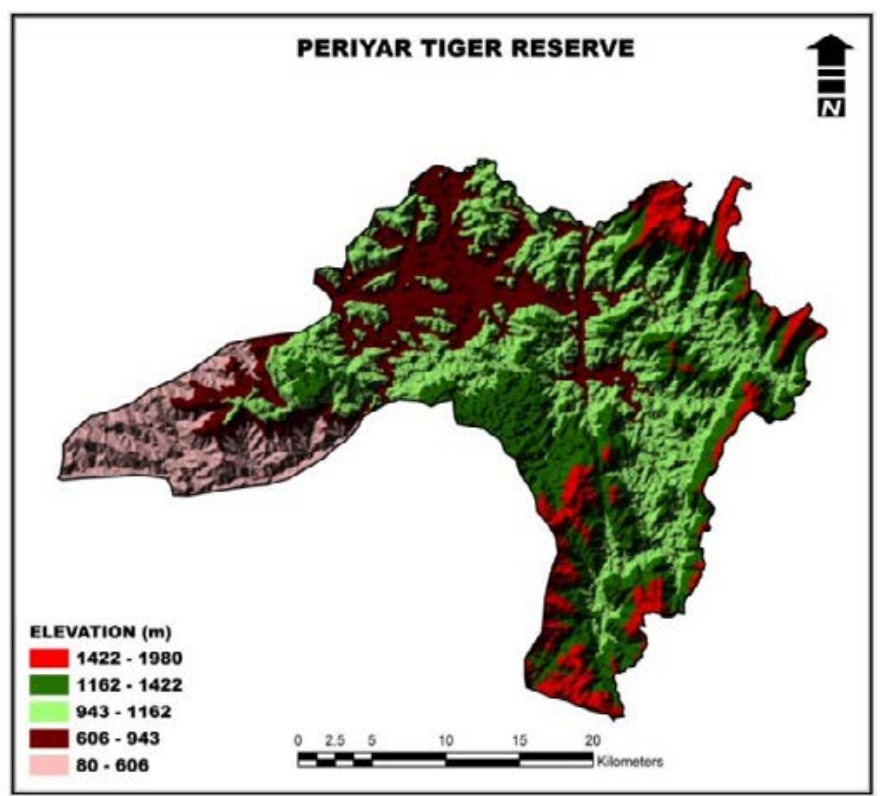

Figure 1 Map of study area

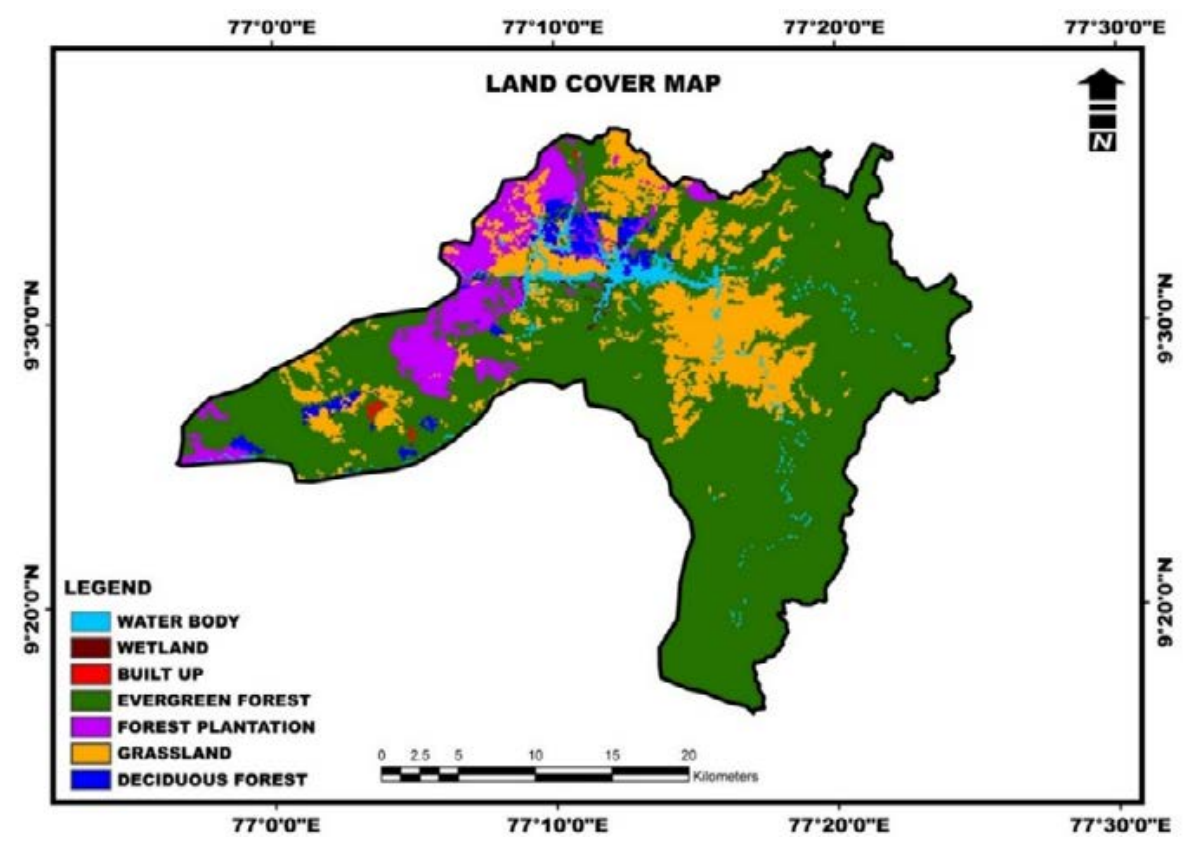

Figure 2 Land cover type map 


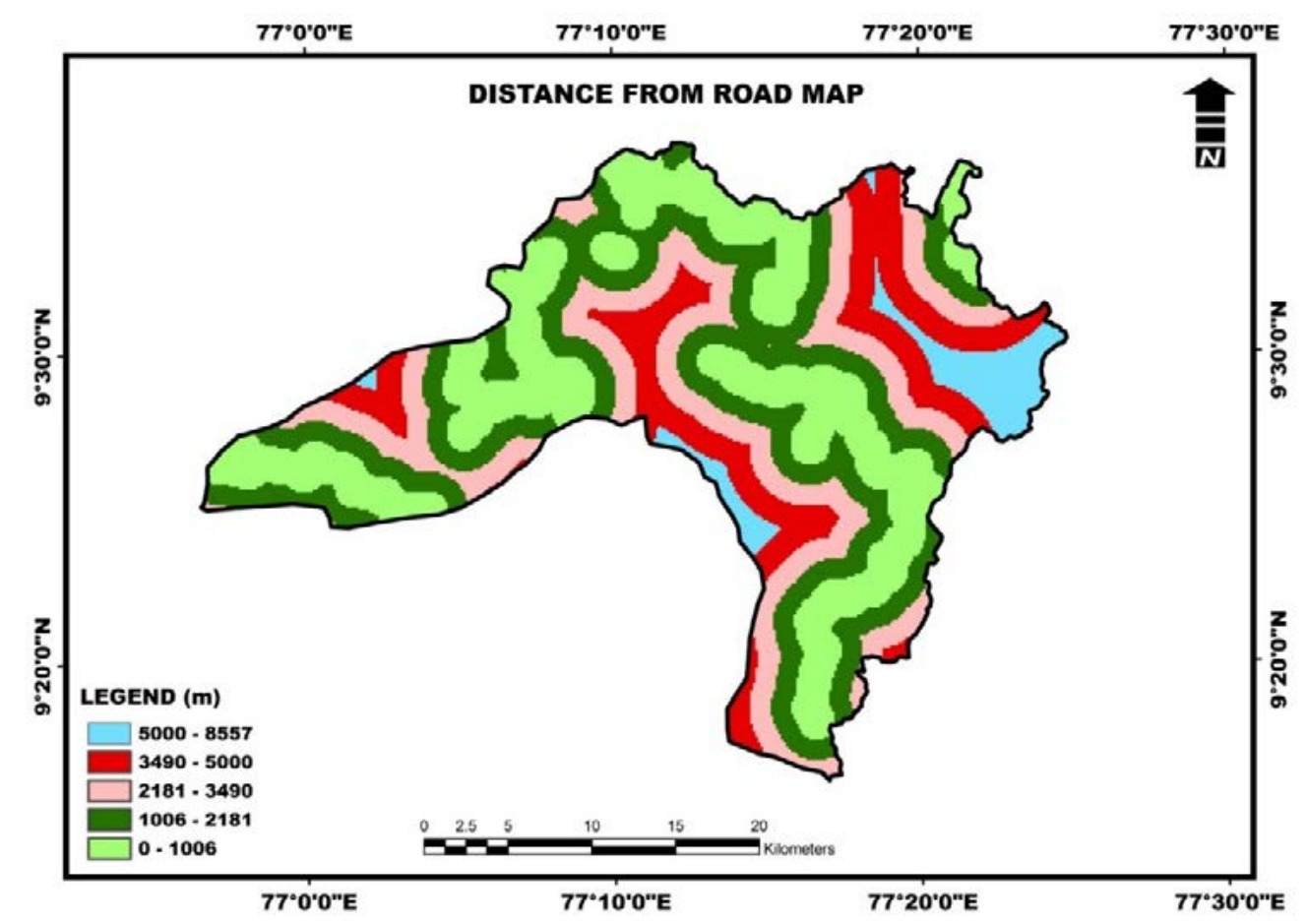

Figure 3 Distance from road map

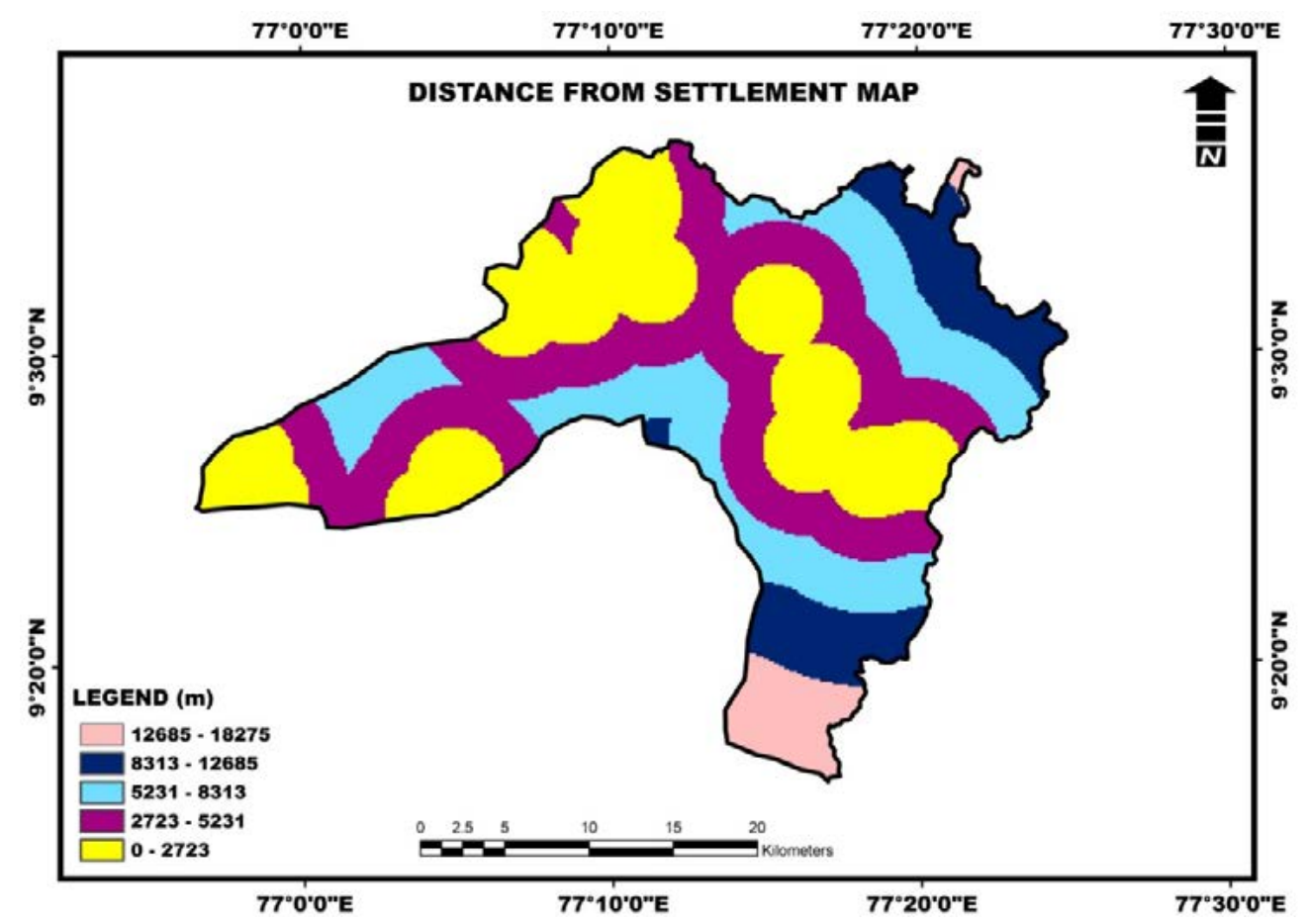

Figure 4 Distance from settlement map 


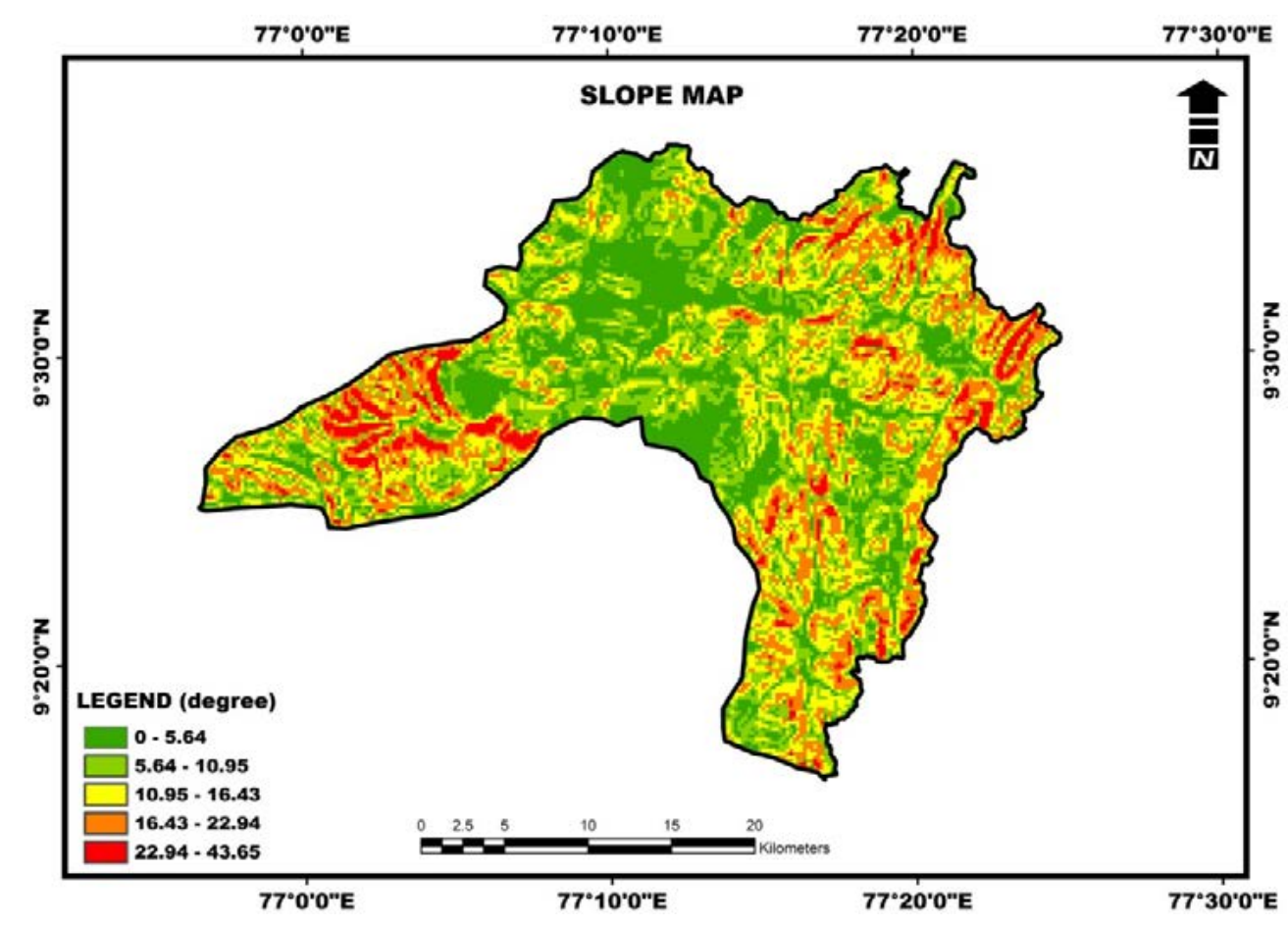

Figure 5 Slope map

Figure 4:

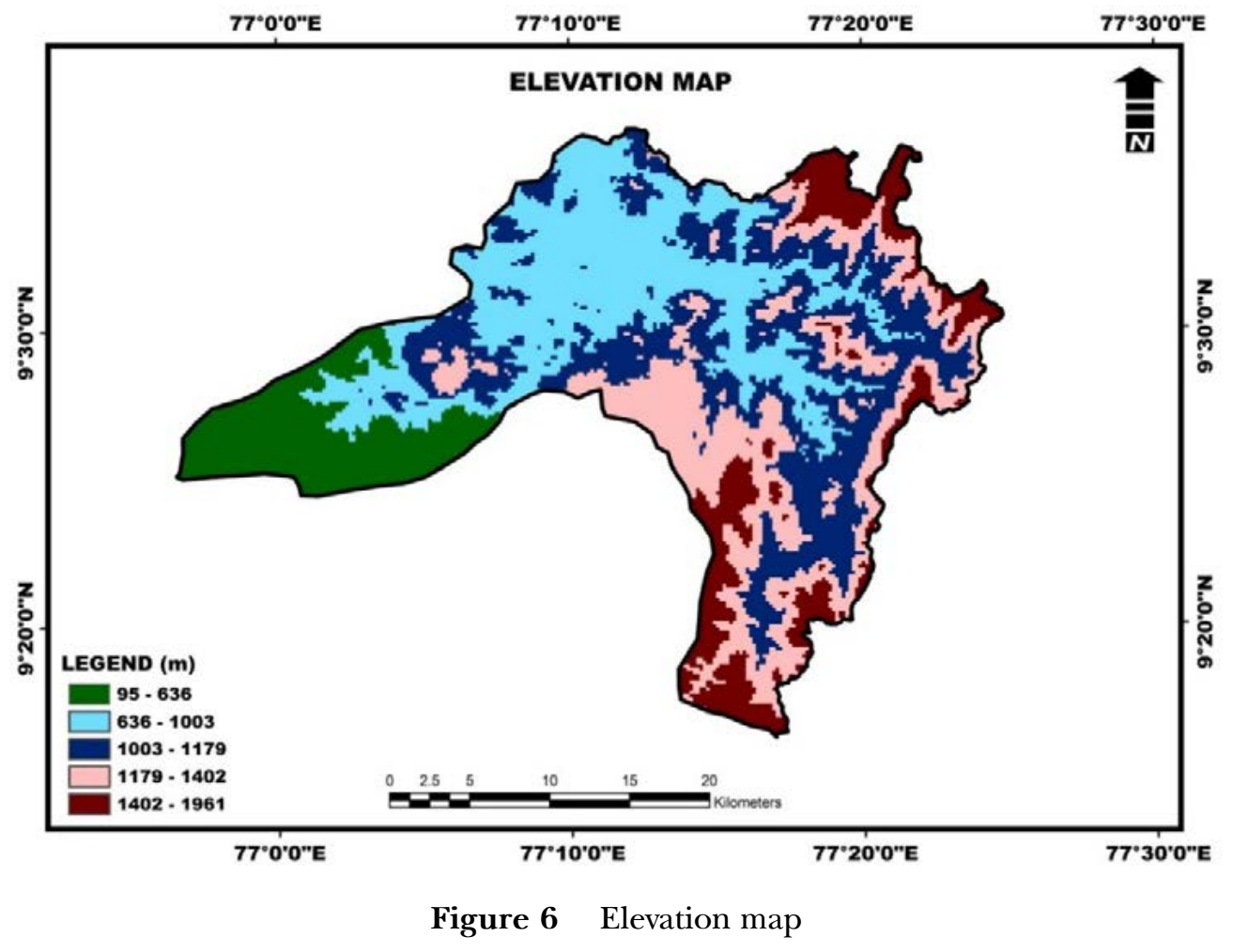




\section{RESULTS AND DISGUSSION}

The fire risk zone map was generated from FRI model by integrating various factors using GIS tools. In the generated map, the area has been classified into five categories: very high, high, moderate, low and very low risk zones, based on fire prone analysis. The results were validated with fire incidents of past 10 years.

The FRI method was used for the demarcation of fire risk zones (Ajin et al. 2014).
The thematic maps of the selected factors were reclassified by ArcGIS natural breaks (Jenks) method. Ranks were assigned to each class of thematic layers and weights were assigned to each thematic layer. The index (Table 1) was derived from the weight and rank (index = weight $\mathrm{x}$ rank). The fire risk zone map (Figure 7) was prepared by overlaying the index maps by using ArcGIS tools. Finally, the risk map was validated with the forest fire inventory points of the forest survey of India.

Table 1 Rank, weight and index assigned for different factors

\begin{tabular}{|c|c|c|c|c|}
\hline Factor & Class & Weight & Rank & Index \\
\hline \multirow{7}{*}{ Land cover type } & Deciduous forest & 7 & \multirow{7}{*}{10} & 70 \\
\hline & Grassland & 6 & & 60 \\
\hline & Forest plantation & 5 & & 50 \\
\hline & Evergreen forest & 4 & & 40 \\
\hline & Built up & 3 & & 30 \\
\hline & Wetland & 2 & & 20 \\
\hline & Water body & 1 & & 10 \\
\hline \multirow{5}{*}{ Slope (degree) } & $0-5.64$ & 1 & \multirow{5}{*}{3} & 3 \\
\hline & $5.64-10.95$ & 2 & & 6 \\
\hline & $10.95-16.43$ & 3 & & 9 \\
\hline & $16.43-22.94$ & 4 & & 12 \\
\hline & 22.94-43.65 & 5 & & 15 \\
\hline \multirow{5}{*}{$\begin{array}{l}\text { Distance from } \\
\text { settlement }(m)\end{array}$} & $0-2723$ & 5 & \multirow{5}{*}{2} & 10 \\
\hline & $2723-5231$ & 4 & & 8 \\
\hline & $5231-8313$ & 3 & & 6 \\
\hline & 8313-12685 & 2 & & 4 \\
\hline & $12685-18275$ & 1 & & 2 \\
\hline \multirow{5}{*}{$\begin{array}{l}\text { Distance from road } \\
(\mathrm{m})\end{array}$} & 0-1006 & 5 & \multirow{5}{*}{2} & 10 \\
\hline & 1006-2181 & 4 & & 8 \\
\hline & 2181-3490 & 3 & & 6 \\
\hline & $3490-5000$ & 2 & & 4 \\
\hline & $5000-8557$ & 1 & & 2 \\
\hline \multirow{5}{*}{ Elevation (m) } & $95-636$ & 1 & \multirow{5}{*}{1} & 1 \\
\hline & $636-1003$ & 2 & & 2 \\
\hline & 1003-1179 & 3 & & 3 \\
\hline & $1179-1402$ & 4 & & 4 \\
\hline & $1402-1961$ & 5 & & 5 \\
\hline
\end{tabular}




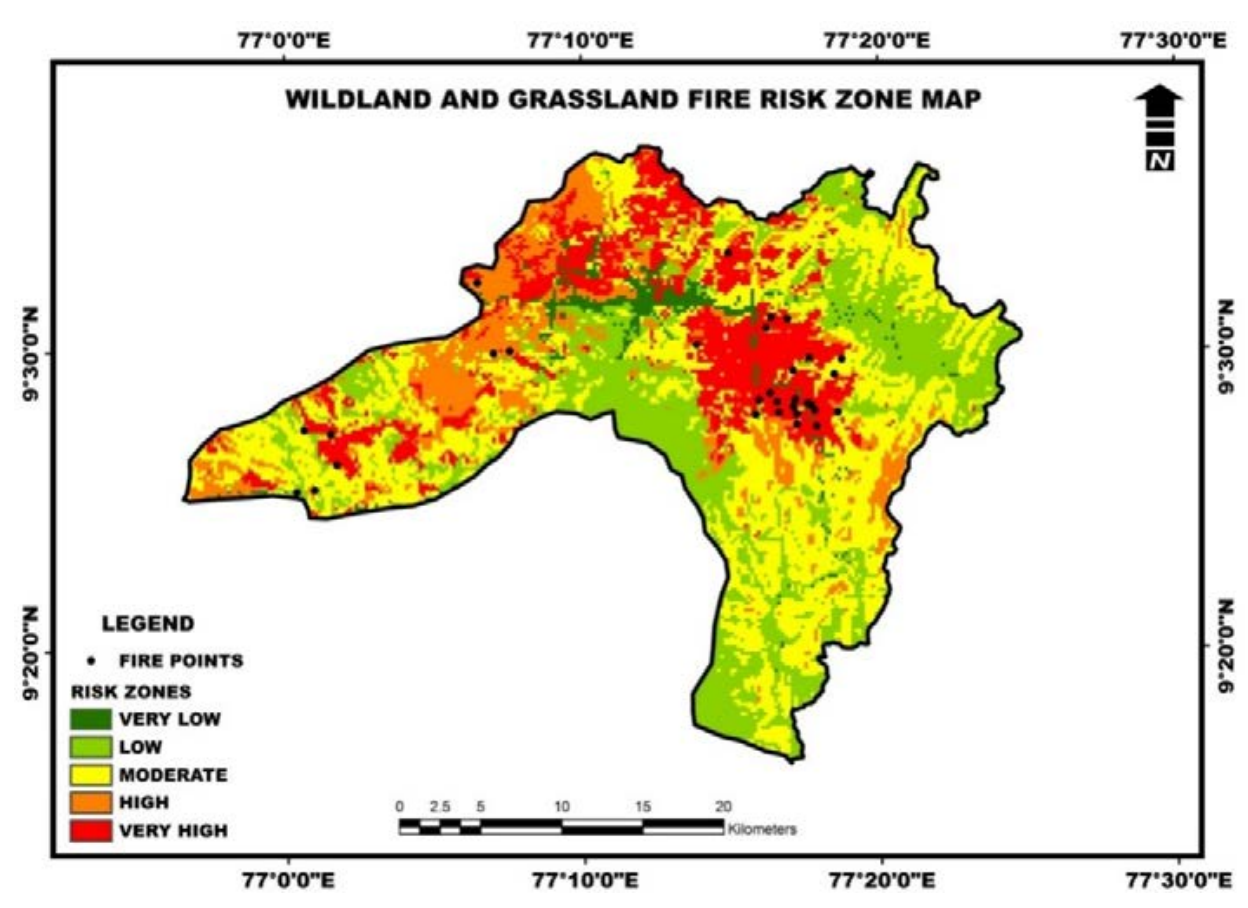

Figure 7 Fire risk zone map

The index maps (slope, elevation, land cover type, distance from road and distance from settlement) were combined by GIS tools to prepare the fire risk zone map. The areas have been classified into five categories: very high, high, moderate, low and very low risk zones. The prepared risk zone map was validated with fire inventory point data collected from forest survey of India and during the field visit. It shows that out of 31 forest fires (2004-2014), 25 forest fires occurred in high and very high risk zones $(80.64 \%), 4$ occurred in moderate risk zones $(12.90 \%)$ and 2 occurred in low and very low risk zones $(6.45 \%)$. The GIS can be used as an effective tool to help planners and decision makers in identifying fire prone areas.

The mitigation procedure for fire management can be implemented considering the following points:

\section{Awareness program and acceptance}

To convince stakeholders for non-tangible benefits may be difficult, for which awareness program needs to be organised prior to implementation.

\section{Behavioral aspects of stakeholders}

The feasibility studies of consumer choice behavior in social systems led to the development of behavioral perspective model, which is helpful to understand the functional relationship of stakeholders and problems, and its consequences (Foxall 2010). The behavior analysis offers a conceptual and methodological system that makes extensive behaviorenvironmental analysis, possibly leading to a behavioral psychological investigation of economic behavior (DiClemente \& Hantula 2003). Behavior analysis can thus aid in constructing a variable account of behavioral patterns exhibited through observation, quantification and scientific interpretation (Nicholson 2005).

\section{Economics of stakeholders}

The economic status of stakeholders is to be critically evaluated before implementing mitigation procedures. The stakeholders of the forest margins are of mainly mid or lowincome groups and are mainly agriculturalists, hence, thoughts of monitory gain dominate, 
rather than service priorities. Immediate income benefits prioritise rather than long term service benefits.

\section{Improvement of quality of life}

The goal of any management plan is to improve the quality of life. This should be achieved without cutting the privileges of the stakeholders. The total ban of resource utilisation is not acceptable, but a wise plan of restricted use of forest resources will help the fire management programmes. The triggering factors for fire and its magnitude are to be addressed and discussed with stakeholders, and the need for controlling forest fire is to be included as a part of the environmental marketing strategy.

\section{Techniques of Marketing Strategies Based on Economics, Behavior and Gender}

To get acceptance from stakeholders for the implementation of the action plan, suitable marketing strategies should be evolved, since most of the activities are targeting on non-tangible benefits. As a consumer, accomplishment is one of the key characters where he or she can achieve personal gain (utilitarian reinforcement approach) or gain informational reinforcement (informational reinforcement approach). The utilitarian reinforcement is provided by the direct benefit gained, and the informational reinforcement is gained by social appreciation from social media (Vishnu-Menon 2016). As in the case of fire management, there is neither utilitarian gain nor social appreciation from media or the government. Hence, there is no doubt that the stakeholder involvement in forest fire management is usually negligible.

\section{Implementation hazards}

Most of the fire management action plans are aiming towards a long-term goal of achieving an eco-friendly environment, however, the stakeholders of the vicinity are expecting immediate benefit by participating in the programme. Thus, convincing the stakeholders for active participation is one of the major tasks of the implementation. With the help of modern technologies like geomatics, it is possible to analyse the factors affecting forest fire using "weightage index" method. The potential area prone to forest fire and fire promoting aspects, and its magnitude can be evaluated using these techniques. A mitigation strategy and action plan can be formulated. The tangential and non-tangential services are studied critically, and the socio-economic statuses of the stakeholders are considered before implementing policy decisions. In most of the government implementing programmes, the service benefits are of secondary importance, and the direct and immediate benefits are of top priority. Hence, some sort of indirect marketing strategies is to be adopted for implementing conservation-oriented policies especially with that of low- and midincome groups and agriculturists in the near vicinity of forests.

\section{GONGLUSIONS}

Advancements in RS technology and GIS will help in real time monitoring, early warning and quick damage assessment of fire disasters. By overlaying or combining different geographical layers, fire prone areas can be identified and targeted for the mitigation of fire disasters.

Based on the studies the forest fire scenario was critically analysed before formulating a fire management strategy for the area. Since the fire promoting factors and their magnitude were different at different regions, similar studies are required as a precursor of the activity. The management plans developed from such studies will form the foundation of the fire management action plan.

\section{ACKNOWLEDGEMENTS}

The authors gratefully acknowledge the logistic support received from Kerala State Forest Department, during the field visit. The technical support from Kerala Forest Research Institute (KFRI) Peechi, Massey Business School, Massey University, Wellington, New Zealand and Cochin University of Science and Technology (CUSAT), Kerala, India, are highly appreciated. 


\section{REFERENCES}

Ajin RS, Mathew KJ, Menon ARR \& Vinod PG. 2014. Forest fire risk analysis using geo-information technology: a study of Peppara Wildlife Sanctuary, Thiruvananthapuram, Kerala, India. Pp 160-165 in Prdeepkumar AP (ed) Proceedings of the $2^{\text {nd }}$ Disaster Risk and Vulnerability Conference. 24-26 April 2014, Thiruvananthapuram.

Chavan ME, Das KK \& Suryawanshi RS. 2012. Forest fire risk zonation using Remote Sensing and GIS in Huynial watershed, Tehri Garhwal district, UA. International Journal of Basic and Applied Research 2: 6-12.

Chuvieco E \& Congalton RG. 1989. Application of remote sensing and geographic information system to forest fire hazard mapping. Remote Sensing of Environment 29: 147-159.

DiClemente DF \& Hantula DA. 2003. Optimal foraging online: increasing sensitivity to delay. Psychology $\mathcal{E}$ Marketing 20: 785-809. doi:10.1002/mar.10097.

Foxall GR. 2010. Consumer behaviour analysis. In Bagozzi RP \& Ruvio A (eds) Consumer Behaviour. International Encyclopaedia of Marketing. John Wiley, New York. https://doi. org/10.1002/9781444316568.wiem03032

Ghobadi GJ, Gholizadeh B \& Dashliburun OM. 2012. Forest fire risk zone mapping from geographic information system in Northern Forests of Iran (case study, Golestan province). International Journal of Agriculture and Crop Sciences 4: 818-824.

Jaiswal RK, Mukherjee S, Raju KD \& Saxena R. 2002. Forest fire risk zone mapping from satellite imagery and GIS. International Journal of Applied Earth Observation and Geoinformation 4: 1-10.

KFRI (Kerala Forest Research Institute). 2010. Fire Related Ecosystem Dynamics of Moist Deciduous Forests of Western Ghats. KFRI Research Report. Kerala Forest Research Institute, Kerala.

Nambimanavalan R \& Jayalakshmi S. 2013. Forest fire risk and degradation assessment using Remote Sensing and GIS. Journal of Geomatics 7: 198-205.

Nicholson M. 2005. Consumer psychology as the behaviourist views it: an operant analysis of consumer channel choice. PhD thesis. Durham University, Durham. http://core.ac.uk/ download/ files/32/108946.

Paul-Antoine S, Andrew S, Dominique M \& William EM. 2011. Forest fire research: the latest advances tools for understanding and managing wild land fire. Journal of Combustion 1: 418756. https://doi.org/10.1155/2011/418756.

Romme WH. 1982. Fire and landscape diversity in subalpine forest of Yellowstone National Park. Ecological Mongraphs 52: 199-221.

SATENDRA \& KAUShIK AD. 2014. Forest Fire Diaster Management. National Institute of Disaster Management, Ministry of Home Affairs, New Delhi.

SOWmya SV \& SomasheKar RK. 2010. Application of remote sensing and geographical information system in mapping forest fire risk zone at Bhadra wildlife sanctuary, India. Journal of Environmental Biology 31: 969-974.

Srivastava P \& Garg A. 2013. Forest Fire in India: Region and Temporal analysis. Journal of Tropical Forest Science 25: 228-239.

Vishnu-Menon RG. 2016. Consumer behavior analysis: relevance and implications for digital marketing. $\mathrm{PhD}$ thesis, Reykjavic University, Iceland.

Whittaker RH. 1978. Ordination of Plant Communities. Springer, Berlin. 